\title{
Nasal Bubble Continuous Positive Airway Pressure: An Experience in a Neonatal Unit in a Tertiary Teaching Hospital in Pokhara
}

\section{Sahisnuta Basnet, Suraj Adhikari and Aparna Mishra}

Department of Paediatrics, Manipal College of Medical Sciences, Pokhara, Nepal

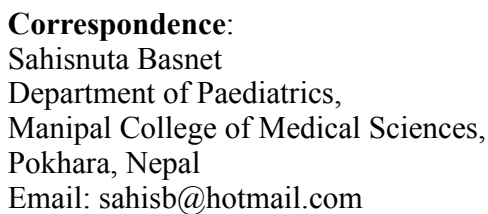

Email: sahisb@hotmail.com

DOI: $10.3126 /$ jnps.v41i2.34392

Submitted on: 2021-01-20

Accepted on: 2021-06-27

Acknowledgements: None

Funding: Nil

Conflict of Interest: None declared

Permission from IRB: Yes
To cite this article: Basnet $S$, Adhikari $S$, Mishra A. Nasal Bubble Continuous Positive Airway Pressure: An Experience in a Neonatal Unit in a Tertiary Teaching Hospital in Pokhara. J Nepal Paediatr Soc. 2021;41(2):205-10.

\section{ABSTRACT}

Introduction: Nasal bubble continuous positive airway pressure (NBCPAP) is a modality used for respiratory distress in newborns and provides respiratory support by preventing atelectasis and reducing the work of breathing. The objective of this study was to determine the efficacy, outcomes and complications of NBCPAP in term and preterm newborns requiring NBCPAP.

Methods:A prospective observational study was conducted on 75 neonates with mild to moderate respiratory distress requiring respiratory support from August 2020 to December 2020. Assessment of baseline characteristics, indications, complications and outcomes of NBCPAP was carried out on the studied newborns. Outcomes were considered as either success (improvement) or failure (need for mechanical ventilation).

Results: The median gestational age was 38 weeks (IQR:35-39 weeks). The median birth weight was 2600 gm (IQR: 2000- 3000 $\mathrm{gm})$. The commonest indication for the requirement of NBCPAP was neonatal sepsis (34\%). A total of $65(86.7 \%)$ neonates could be successfully weaned off NBCPAP. Complications were noted in 23 neonates. Modified Downes score on admission (adjusted OR 5.34, 95\% CI 1.75- 16.35) and gestational age (adjusted OR 0.68, $95 \%$ CI $0.51-0.92$ ) were independent predictors of failure of NBCPAP.

Conclusions: NBCPAP can be successfully utilised in preterm and term babies with mild to moderate respiratory distress. The major predictors of failure of NBCPAP are decreasing gestational age and increasing Downes score.

Keywords: Downes score; neonates; respiratory distress; respiratory support

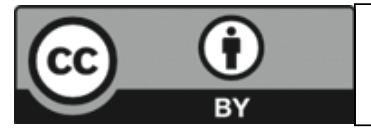

This work is licensed under creative common attribution 3.0 license 


\section{INTRODUCTION}

Nasal bubble continuous positive airway pressure (NBCPAP) is a respiratory support delivered to a spontaneously breathing patient. ${ }^{1}$ It is a noninvasive ventilator support and an essential component of neonatal care which has contributed towards an improved overall outcome in the management of neonates with respiratory distress. ${ }^{2,3}$ By utilising NBCPAP, positive end expiratory pressure (PEEP) is delivered through a water column using a bottle or bag which supports the respiratory system by preventing atelectasis, maintaining airway stability and stabilising the chest wall. ${ }^{4,5}$

NBCPAP is used in respiratory distress syndrome (RDS), meconium aspiration syndrome (MAS), congenital pneumonia, transient tachypnea of the newborn (TTNB), pulmonary edema, apnea and post extubation in neonates. It can be used as a first line respiratory support and has shown to decrease the requirement of mechanical ventilation. ${ }^{3}$ NBCPAP has gained popularity due to its simple mechanism; it is easily assemblable, cost effective and has shown good results without significant complications. ${ }^{6-8}$ Complications noted include skin abrasions, necrosis of the nasal septum, pneumothorax, gastric distention and feeding intolerance. $^{9}$

Data regarding NBCPAP have been found to be lacking in Western Nepal. Therefore this study has been conceptualised to determine the efficacy, outcomes and complications of NBCPAP in neonates requiring respiratory support in Manipal Teaching Hospital, Pokhara, Nepal.

\section{METHODS}

This was a hospital based prospective observational study carried out in the neonatal intensive care unit (NICU) of Manipal Teaching Hospital, Pokhara, Nepal from August 2020 to December 2020. Newborns above 26 weeks of gestational age and up to 28 days of life were included in the study. Neonates with respiratory distress, but spontaneously breathing and meeting the criteria to be commenced on continuous positive airway pressure (CPAP) were started on NBCPAP. The criteria used in NICU for the instigation of NBCPAP were: babies not maintaining saturation $\left(\mathrm{SPO}_{2}<90 \%\right)$ on oxygen delivered via nasal prongs or oxygen hood box, ${ }^{1}$ babies with $\geq 3$ episodes of apnea over an hour, ${ }^{1}$ babies with Downes' score of $\geq 3 .^{1,10}$ (A score of 3 was considered mild respiratory distress and scores 4 - 6 was considered as moderate respiratory distress). Exclusion criteria included neonates with congenital anomaly such as oro-facial deformity including cleft lip and palate, trachea-esophageal fistula, congenital diaphragmatic hernia and a Downes score of $\geq 7$ requiring intubation. Sample size was calculated based on single population proportion formula using efficacy of NBCPAP of $87 \%$ from a similar study, margin of error of 0.08 and $\mathrm{Z}$ - score of 1.96 for $95 \%$ confidence interval. ${ }^{11}$ A $10 \%$ non-response rate was added and so a total of 75 consecutive neonates requiring NBCPAP was the calculated sample size. NBCPAP that was utilised in our study was a self-setup system. It was administered using a circuit of tubing attached to central oxygen source with a humidifier. Neonatal nasal prongs was used as the interface for setting up the CPAP system and a water seal bag was filled to a predetermined level with sterile water to generate the PEEP to the depth to which the expiratory limb of the CPAP was immersed. PEEP was started at 5 $\mathrm{cm} \mathrm{H}_{2} \mathrm{O}$ and increased up to $8 \mathrm{~cm} \mathrm{H}_{2} \mathrm{O}$ depending on the neonates response measured by the $\mathrm{SPO}_{2}$, severity of chest retractions and Downes score. NBCPAP was considered to be successful if the baby could be weaned off using the following criteria- respiratory rate $<60 /$ minute, no or minimal chest retractions, $\mathrm{SPO}_{2}>95 \%$ maintained with oxygen delivered via nasal prongs or hood box after weaning from the NBCPAP for four consecutive hours and Downes score of $<3$.We considered NBCPAP to have failed if the child needed intubation and mechanical ventilation based on a respiratory rate $>60$ /minute with $\mathrm{SPO}_{2}<90 \%$ on a PEEP of $8 \mathrm{~cm} \mathrm{H} 2 \mathrm{O}$, a Downes score of $\geq 7$ or if the baby had recurrent apneic episodes. In addition to the NBCPAP, the study subjects received standard and specific treatment in accordance with their specific diagnosis.Demographics of the neonates, diagnosis, age at the start of NBCPAP, its duration, outcome and complications of the baby was recorded. Both descriptive and analytical statistical analyses were done using Statistical Package for Social Sciences (SPSS) version 23. All categorical variables were compared for the study outcome by using the Fisher exact test or $\chi^{2}$ test, and continuous 
variables were compared using the $t$ test or the Mann-Whitney $U$ test, as appropriate. Continuous data were expressed as mean (SD) or median \{interquartile range (IQR)\} values. Multivariate logistic regression was performed to determine the independent predictors of outcome. $\mathrm{P}<0.05$ was considered statistically significant.

\section{RESULTS}

The study population included 75 neonates requiring NBCPAP. The median age was four days (IQR: 1 - 6 days, Range: 1 - 18 days) and 43 $(57.3 \%)$ were males. The median gestational age according to New Ballard's score was 38 weeks (IQR: 35-39 weeks), out of which 34 (45.3\%) were premature. The median birth weight was $2600 \mathrm{gm}$ (IQR: 2000 - $3000 \mathrm{gm})$, of which 34 (45.3\%) were low birth weight. The number of babies born via cesarean section was 32 (42.7\%). More than 90\% of mothers had no underlying illness. The most common indication of NBCPAP was neonatal sepsis $\{34 \%(25)\}$ followed by RDS. Based on modified Downes score, 41 (54.7\%) neonates had mild respiratory distress and $34(45.3 \%)$ had moderate respiratory distress on admission. The neonates required NBCPAP for a median of three days (IQR: 2 - 4 days). A total of 65 (86.7\%) neonates could be weaned off successfully of NBCPAP including nine (12\%) neonates leaving against medical advice and two $(2.7 \%)$ neonates who were referred to higher centres. These neonates were weaned off before discharge. Remaining ten needed intubation and mechanical ventilation for desaturation and deteriorating modified Downes score despite maximum permissible $\mathrm{FiO}_{2}$ and PEEP. However, only five of these cases survived. All of the mortality cases were preterm babies with respiratory distress syndrome. The median hospital stay was five days (IQR: 4 - 9 days). In our study, 23 (30.7\%) neonates had one or more complications of NBCPAP, out of which all cases of failure had complications. The most frequent complication was abdominal distension in $10(13.3 \%)$ neonates although oro-gastric tube was placed in all neonates on NBCPAP. The baseline characteristics and outcome of these neonates are presented in Table 1.

Compared with neonates who were successfully weaned off $(n=65)$, those requiring further interventions $(\mathrm{n}=10)$ were pre-term $\{38$ weeks
(IQR: 36.5 - 39 weeks) vs. 32 weeks (IQR: 28 - 37 weeks), $\mathrm{p}<0.001\}$ with low birth weight $\{2700 \mathrm{gm}$ (IQR: 2095 - 3130 gm) vs. 1600 gm (IQR: 982.50 2650 grams), $\mathrm{p}<0.001\}$ and higher modified Downes score on admission (Median: 3 vs. 5), $\mathrm{p}<$ $0.001\}$. Failure cases tend to be on NBCPAP for more number of days as compared to neonates who didn't require intubation $\{2$ days (IQR: 2 - 4 days) vs. 5 days (IQR: $2-5.25$ days), $\mathrm{p}<0.001\}$. Also, these neonates were more likely to have complications of NBCPAP $(p<0.001)$. All the failure cases had one or more complications.

Table 2 shows the results of multivariate logistic regression model. Modified Downes score on admission \{adjusted odds ratio (OR) 5.34, 95\% confidence interval (CI) $1.75-16.35\}$ and gestational age \{adjusted OR $0.68,95 \%$ CI 0.51 $0.92\}$ were independent predictors of failure of NBCPAP.

\section{DISCUSSION}

The importance of CPAP is well demonstrated in high resource settings but this study examines the use of a locally made system in an under resourced setting in neonates. This study demonstrates the use of NBCPAP in both full term and preterm neonates with respiratory distress. Most of the newborns in our study were term neonates $(60 \%)$. This finding is the similar to a study carried out in Kathmandu Medical College, Kathmandu, Nepal where it was observed that $60 \%$ of their study population was term. ${ }^{12}$ These findings suggest that the availability of this respiratory support is useful to all the neonates developing respiratory distress and not just to preterm neonates who are more prone to develop RDS.

Neonatal sepsis was seen as the commonest indication for NBCPAP in our study. However, many studies presented RDS as the commonest indication of NBCPAP. ${ }^{1,4,13,14}$ The explanation for this is that in our study, most of the neonates included were term whereas it was seen that the proportion of preterms were higher in the compared studies and respiratory distress is more common in preterms. Also, it is possible that some of our cases of preterm with RDS did not meet our inclusion criteria and were put on mechanical ventilator since the start of admission due to a high Downes score. Other diagnosis for the indications of NBCPAP in 
Table 1. Baseline characteristics and outcome of neonates on NBCPAP

\begin{tabular}{|c|c|c|c|c|}
\hline Characteristics & $\begin{array}{l}\text { Total (No, \%) } \\
\quad(\mathrm{N}=75)\end{array}$ & $\begin{array}{l}\text { Success, (No, \%) } \\
\quad(N=65)\end{array}$ & $\begin{array}{l}\text { Failure, (No, \%) } \\
\qquad(\mathrm{N}=10)\end{array}$ & p - value \\
\hline $\begin{array}{l}\text { Gender } \\
\qquad \begin{array}{l}\text { Male } \\
\text { Female }\end{array}\end{array}$ & $\begin{array}{r}43(57.3) \\
32(42.7)\end{array}$ & $\begin{array}{l}36(55.4) \\
29(44.6)\end{array}$ & $\begin{array}{l}7(70.0) \\
3(30.0)\end{array}$ & 0.384 \\
\hline $\begin{array}{l}\text { Gestational age (weeks) Median (IQR) } \\
\quad<34 \\
34-<37 \\
>37\end{array}$ & $\begin{array}{r}38(35-39) \\
11(14.7) \\
23(30.7) \\
41(54.7)\end{array}$ & $\begin{array}{r}38(36.5-39) \\
5(7.7) \\
21(32.3) \\
39(60.0)\end{array}$ & $\begin{array}{r}32(28-37) \\
6(60.0) \\
2(20.0) \\
2(20.0)\end{array}$ & $<0.001$ \\
\hline Age of baby(days) Median (IQR) & $4(1-6)$ & $4(2-6.5)$ & $1(1-5.25)$ & \\
\hline $\begin{array}{c}\text { Birth weight (grams) Median (IQR) } \\
<1500 \\
1500-2499 \\
>2500\end{array}$ & $\begin{array}{r}2600(2000-3000) \\
5(6.7) \\
29(38.7) \\
41(54.7)\end{array}$ & $\begin{array}{r}2700(2095-3130) \\
1(1.5) \\
26(40.0) \\
38(58.5)\end{array}$ & $\begin{array}{r}1600(982.5-2650) \\
4(40.0) \\
3(30.0) \\
3(30.0)\end{array}$ & $<0.001$ \\
\hline $\begin{array}{l}\text { Mode of delivery } \\
\text { Vaginal } \\
\text { Instrumental } \\
\text { Cesarean section }\end{array}$ & $\begin{array}{r}39(52.0) \\
4(5.3) \\
32(42.7)\end{array}$ & $\begin{array}{r}34(52.3) \\
3(4.6) \\
28(43.1)\end{array}$ & $\begin{array}{l}5(50.0) \\
1(10.0) \\
4(40.0)\end{array}$ & 0.779 \\
\hline $\begin{array}{l}\text { Initial modified Downes score (Median) } \\
\text { Mild (Score 3) } \\
\text { Moderate (Scores } 4-6)\end{array}$ & $\begin{array}{r}3 \\
41(54.7) \\
34(45.3)\end{array}$ & $\begin{array}{r}3 \\
41(63.1) \\
24(36.9)\end{array}$ & $\begin{array}{r}5 \\
0(0) \\
10(100)\end{array}$ & $<0.001$ \\
\hline $\begin{array}{l}\text { Diagnosis } \\
\text { Neonatal sepsis } \\
\text { Respiratory distress syndrome } \\
\text { Meconium aspiration syndrome } \\
\text { Perinatal asphyxia } \\
\text { Transient tachypnea of newborn } \\
\text { Congenital Pneumonia }\end{array}$ & $\begin{array}{r}25(33.3) \\
20(26.7) \\
10(13.3) \\
6(8.0) \\
6(8.0) \\
8(10.7)\end{array}$ & $\begin{array}{r}25(38.5) \\
12(18.5) \\
8(12.3) \\
6(9.2) \\
6(9.2) \\
8(12.3)\end{array}$ & $\begin{array}{r}0(0) \\
8(80.0) \\
2(20.0) \\
0(0) \\
0(0) \\
0(0)\end{array}$ & \\
\hline $\begin{array}{l}\text { Duration of hospital stay in days, } \\
\text { Median (IQR) } \\
\begin{array}{c}<3 \\
3-6 \\
7-13 \\
>14\end{array}\end{array}$ & $\begin{array}{r}5(4-9) \\
6(8.0) \\
48(64.0) \\
17(22.7) \\
4(5.3)\end{array}$ & \begin{tabular}{r|}
$5(4-8)$ \\
$6(9.2)$ \\
$42(64.6)$ \\
$14(21.5)$ \\
$3(4.6)$
\end{tabular} & $\begin{array}{r}6.5(5.75-11.50) \\
0(0) \\
6(60.0) \\
3(30.0) \\
1(10.0)\end{array}$ & 0.638 \\
\hline $\begin{array}{l}\text { Duration on NBCPAP (days) Median } \\
\text { (IQR) } \\
\begin{array}{l}1-2 \\
3-4 \\
>4\end{array}\end{array}$ & $\begin{array}{l}3(2-4) \\
36(48.0) \\
24(32.0) \\
15(10.0)\end{array}$ & $\begin{array}{r}2(2-4) \\
33(50.8) \\
24(36.9) \\
8(12.3)\end{array}$ & $\begin{array}{r}5(2-5.25) \\
3(30.0) \\
0(0) \\
7(70.0)\end{array}$ & $<0.001$ \\
\hline $\begin{array}{l}\text { Maternal illness } \\
\text { None } \\
\text { Pregnancy induced Hypertension } \\
\text { Gestational Diabetes mellitus } \\
\text { Systemic Hypertension }\end{array}$ & $\begin{array}{r}68(90.7) \\
5(6.7) \\
1(1.3) \\
1(1.3)\end{array}$ & $\begin{array}{r}60(92.3) \\
3(4.6) \\
1(1.5) \\
1(1.5)\end{array}$ & $\begin{array}{r}8(80.0) \\
2(20.0) \\
0(0) \\
0(0)\end{array}$ & 0.317 \\
\hline $\begin{array}{l}\text { Final outcome } \\
\text { Discharged } \\
\text { Leave Against Medical Advice } \\
\text { Referred } \\
\text { Death }\end{array}$ & $\begin{array}{r}59(78.7) \\
9(12.0) \\
2(2.7) \\
5(6.7)\end{array}$ & - & - & \\
\hline $\begin{array}{l}\text { Complications } \\
\text { Abdominal distension } \\
\text { Recurrent apnea } \\
\text { Skin abrasions } \\
\text { Nasal septum necrosis }\end{array}$ & $\begin{array}{r}23(30.7) \\
10(13.3) \\
9(12.0) \\
9(12.0) \\
6(8.0)\end{array}$ & $\begin{array}{r}13(20.0) \\
6(9.2) \\
0(0) \\
7(10.8) \\
2(3.1)\end{array}$ & $\begin{array}{r}10(100) \mathrm{a} \\
4(40.0) \\
9(90.0) \\
2(20.0) \\
4(40.0)\end{array}$ & \\
\hline $\begin{array}{c}\text { Total number of complications } \\
\text { No complication } \\
\text { One complication } \\
\text { Two complications } \\
\text { Three complications }\end{array}$ & $\begin{array}{r}52(69.3) \\
13(17.3) \\
9(12.0) \\
1(1.3)\end{array}$ & $\begin{array}{r}52(80.0) \\
11(16.9) \\
2(3.1) \\
0(0)\end{array}$ & $\begin{array}{r}0(0) \\
2(20.0) \\
7(70.0) \\
1(10.0)\end{array}$ & $<0.001$ \\
\hline
\end{tabular}

\footnotetext{
a. Sum of percentage is more than 100 as neonates had more than one complication.
} 
Table 2. Multivariate logistic regression analysis of predictors for failure of NBCPAP

\begin{tabular}{|lrcc|}
\hline Variables & $\begin{array}{c}\text { Adjusted } \\
\text { odds ratio }\end{array}$ & 95\% CI & $\begin{array}{c}\text { p - } \\
\text { value }\end{array}$ \\
\hline $\begin{array}{l}\text { Gestational age in } \\
\text { weeks }\end{array}$ & 0.68 & $0.51-0.92$ & 0.012 \\
$\begin{array}{l}\text { Initial modified } \\
\text { Downes score }\end{array}$ & 5.34 & $1.75-16.35$ & 0.003 \\
$\begin{array}{l}\text { Birth weight } \\
\begin{array}{l}\text { Total duration on } \\
\text { NBCPAP, days }\end{array}\end{array}$ & 0.50 & $0.48-5.13$ & 0.556 \\
& 1.28 & $0.69-2.39$ & 0.431 \\
\hline
\end{tabular}

Note: Both backward and forward models used to decide the final model

our study were similar to those cited in other studies though the order of frequencies varied. ${ }^{1,12-14}$

Several studies have shown higher need for respiratory assistance in males. ${ }^{14,15}$ Females have higher levels of surfactant synthesis in intrauterine life explained by different gender related hormonal profiles and this is reflected in our study as majority of the patients were males $(57.3 \%$ vs $42.7 \%)$. In our study $65(86.7 \%)$ newborns were successfully weaned off NBCPAP whereas 10 $(13.3 \%)$ needed intubation. Our failure rate is comparable to that reported by Abdulkadir et al. (15\%) and less than $20 \%$ and $25 \%$ documented by Urs PS et al. and Koti et al. respectively. ${ }^{1,4,5}$ Lower failure rates in our setting could be attributed to the differences in inclusion criteria of the cases involved as in the study by Koti et al., where Downes score of $>7$ was included. ${ }^{5}$ Therefore, we can infer that the included cases being analysed in our study were of a less severe nature resulting in lower failure rates. Modified Downes score also emerged as one of the predictors of failure of NBCPAP in our study. It was seen that for each increase in number of the score, the chances of failure of NBCPAP increased by 5.34 times. Observations made by Abdulkadir et al. and Koti et al. support this findings. ${ }^{1,5}$

Twenty-three (30.7\%) of the 75 neonates developed complications, the most frequent being abdominal distension $\{10(13.3 \%)\}$. It was transient and not life threatening and resolved by aspirating air from oro-gastric tube. Similar observations were made in a study by Ahmed et al. ${ }^{16}$ Skin abrasions in nasal area and cheeks was found in nine (12\%) cases, whereas Mathai et al. reported $30 \%$ cases of skin abrasions. ${ }^{9}$ Their study consisted of only preterm babies whose skin is more delicate and fragile. Complications were not seen in $69.3 \%$ of our patients which is similar to the observation made by Ahmed et al where $75 \%$ of their patients had no complications relating to NBCPAP. ${ }^{16}$

In this study, low gestational age was one of the predictors for failure of NBCPAP which was in agreement with studies by Adb-Allah et al., Arora $\mathrm{V}$ et al. and Pillai MS et al. ${ }^{16-18}$ Prematurity is related to apnea and cardiovascular instability which results in increased severity of disease necessitating mechanical ventilator and thus failure of NBCPAP. Ten newborns needed to be shifted to mechanical ventilation due to worsening condition. Out of this, five babies died with mortality rate of $50 \%$. Abd-Allah et al. reported similar figures of $53.33 \%$ mortality among ventilated patients. ${ }^{14}$

\section{CONCLUSIONS}

This study demonstrates the feasibility of successfully utilising NBCPAP in term and preterm babies with respiratory distress. With this, we can conclude that for those health personnel who are providing care to neonates in a low resource country like Nepal where there is a paucity of ventilators, delivery of NBCPAP is an effective system that can be used for respiratory distress. The major predictors of failure in our study were decreasing gestational age and increasing Downes score. The success rate with this system was $86.7 \%$ in our study.

\section{REFERENCES}

1. Abdulkadir I, Hassan L, Abdullahi F, Purdue S, Ogala WN. Nasal Bubble CPAP: One year experience in a neonatal unit of a tertiary health facility in Northwestern Nigeria. Niger Postgrad Med J. 2015;22(1):21-4. PMID: 25875407 
2. Bahareh BB, Arash M, Pedram N, Mohammad RB. Bubble-CPAP vs Ventilatory- CPAP in preterm infants with respiratory distress. Iran J Pediatr. 2011;21(2):151-8 PMID: 23056781

3. Nowadzky t, Pantoja A, Britton JR. Bubble continuous positive airway pressure, a potentially better practice reduces the use of mechanical ventilation among very low birth weight infants with respiratory distress syndrome. Pediatrics. 2009;123(6):1534-40. DOI: 10.1542/peds.2008-1279

4. Urs PS, Khan F, Maiya PP. Bubble CPAP- a primary respiratory support for respiratory distress syndrome in newborns. Indian Pediatr. 2009;46:409-11. PMID: 19179737

5. Koti J, Murki S, Gaddam P, Reddy A, Reddy MDR. Bubble CPAP for respiratory distress in preterm infants. Indian Pediatr.2010;47:139-43. DOI: 10.1007/s13312-010-0021-6

6. Narendra V, Donovan EF, Hoath SB, Akinbi HT, Steichen JJ, Jobe AH. Early bubble CPAP and outcome in extremely low birth weight babies. J Perinatol. 2003;23:195-9. DOI: 10.1038/sj.jp.7210904

7. Ammari A, Suri M, Milisavljevic V, Sahni R, Bateman D, Sanocka U, et al. Variables associated with early failure of nasal CPAP in very low birth weight infants. J Pediatr. 2005;147:341-7. DOI: 10.1016/j.jpeds.2005.04.062

8. Shrestha M, Basnet S, Shrestha PS. Bubble-CPAP in neonatal unit of TUTH. J Nepal Pediatr Soc. 2010;30: 64-8. DOI: https://doi.org/10.3126/jnps.v30i1.2465

9. Mathai SS, Rajeev A, Adhikari KM. Safety and effectiveness of bubble continuous positive airway pressure in preterm neonates with respiratory distress. Med J Armed Forces India. 2014;70:327-31. DOI: 10.1016/j.mjafi. 2013.08.003

10. Rusmawati A, Haksari E, Naning R. Downes score as a clinical assessment for hypoxemia in neonates with respiratory distress. Paediatr Indones. 2008;48(6):342-5. DOI: https://doi.org/10.14238/pi48.6.2008.342-5

11. Anwaar O, Hussain M, Shakeel M, Baig MMA. Outcome of use of nasal continuous positive airway pressure through infant flow drivers in neonates with respiratory distress in a tertiary care hospital in Pakistan. J Ayub Med Coll. 2018;30(4):511-5. PMID: 30632326

12. Manandhar SR. Outcome of respiratory distress in neonates with bubble CPAP at neonatal intensive care unit of a tertiary hospital. J Nep Med Assoc. 2019;57(216):92-7. PMID: 31477940

13. Byram SK, Y Sivaramakrishna, Raju MS. Outcome of bubble (CPAP) continuous positive airway pressure in neonates with respiratory distress and its failure factors. Int J Contemp Med Res. 2019;6(7):11-3. DOI: http:// dx.doi.org/10.21276/ijcmr.2019.6.7.41

14. Abd-Allah ST, El-Mazary AM, Nagwa IO, Ebtesam EH, Amin AM. Analytical study for neonates with respiratory distress on Bubble Continuous Positive Airway Pressure admitted to NICU of Minia University Hospital. Ann Neo J. 2019;1(1):3-12. DOI: 10.21608/ANJ.2019.45817.

15. Rezzonico R, Caccamo LM, Manfredini V, Cartabia M, Sanchez N, Paredes Z, et al. Impact of the systematic introduction of low-cost bubble nasal CPAP in a NICU of a developing country: a prospective pre- and postintervention study. BMC Pediatr. 2015;15:26. DOI: 10.1186/s12887-015-0338-3

16. Ahmed Z, Shah S, Khan U, Subhani F. Use of indigenously designed nasal bubble continuous positive airway pressure (NB-CPAP) in neonates with respiratory distress-experience from a military hospital. Pak Armed Forces Med J. 2016;66(5):645-50. https://pafmj.org/index.php/PAFMJ/article/view/783

17. Arora V, Gediya SG, Jain R. Outcome of premature babies with RDS using bubble CPAP. Int J Contemp Pediatr. 2017;4(3):939. DOI: 10.18203/2349-3291.ijcp20171702

18. Pillai MS, Sankar MJ, Mani K, Agarwal R, Paul VK, Deorari AK. Clinical prediction score for nasal CPAP failure in pre-term VLBW neonates with early onset respiratory distress. J Trop Pediatr. 2011;4:274-9. DOI: 10.1093/ tropej/fmq047 